\title{
openheart Analysis of safety outcomes for radial versus femoral access for percutaneous coronary intervention from a large clinical registry
}

David R Dobies, ${ }^{1}$ Kimberly R Barber, ${ }^{2}$ Amanda L Cohoon $^{3}$

To cite: Dobies DR, Barber KR, Cohoon AL. Analysis of safety outcomes for radial versus femoral access for percutaneous coronary intervention from a large clinical registry. Open Heart 2016;3:e000397. doi:10.1136/openhrt-2015000397

Received 4 January 2016 Revised 15 June 2016 Accepted 7 July 2016

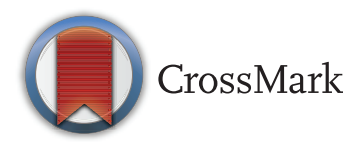

\footnotetext{
${ }^{1}$ Regional Cardiology Associates, Grand Blanc, Michigan, USA

${ }^{2}$ Genesys Regional Medical Center, Office of Research, Grand Blanc, Michigan, USA ${ }^{3}$ Genesys Regional Medical Center, Cardiac Cath Laboratory, Grand Blanc, Michegan, USA
}

Correspondence to Professor Kimberly R Barber; kbarber@genesys.org

\section{ABSTRACT}

Objective: Using a multisite, contemporary registry of 58862 percutaneous coronary intervention ( $\mathrm{PCl}$ ) procedures in a national healthcare system, the present study compared radial access with femoral access on safety and efficacy outcomes.

Methods: This is a real-world, large-scale, retrospective study using clinical data from a 137-hopsital System and reported to a multisite clinical registry. All patients undergoing a cardiac catheterisation procedure were included in this database. The primary end points were major bleeding and radiation exposure. Multivariate logistic regression modelling was used to compare access groups.

Results: Femoral access ( $n=55729$ ) accounted for $94.7 \%$ and radial access ( $n=3137$ ) for $5.3 \%$. There were fewer bleeding events in the radial group $(n=28$, $0.9 \%)$ than those in the femoral group ( $n=1234,2.2 \%)$ in the unadjusted analysis. For patients receiving bivalirudin, bleeding occurred in 337 patients $(1.6 \%)$, and there was no difference in rates between radial access $(n=13,1.1 \%)$ and femoral access $(n=327$, $1.7 \%)(\mathrm{OR}=0.65, \mathrm{Cl} 0.40$ to $1.22, \mathrm{p}=0.19)$. The radial technique resulted in higher radiation exposure in each case, but particularly for procedures involving prior coronary artery bypass graft history and non-STelevated myocardial infarction patients. The mean fluoroscopy time among femoral access procedures was $15.68 \mathrm{~min}(\mathrm{SD}=11.7)$ versus $19.86 \mathrm{~min}(\mathrm{SD}=13.8)$ for radial access procedures $(p<0.0001)$.

Conclusions: Radial access for $\mathrm{PCl}$ is associated with higher fluoroscopy times but not with less major bleeding when bivalirudin is used. Our analysis, combined with other study findings, suggest that the safest route for PCI may be the use of femoral access with bivalirudin.

\section{INTRODUCTION}

Radial access for percutaneous coronary intervention (PCI) has been presented in the research literature as superior to femoral access in terms of lower bleeding rates and other outcomes. Large, randomised, controlled trials (RCTs) demonstrate superiority

\section{KEY QUESTIONS}

What is already known about this participant?

- Randomised, controlled trials demonstrate superiority of radial access for some major outcomes such as bleeding. There are limited data regarding radial use and radiation exposure from clinical data. The ability to generalise to clinical practice is limited.

What does this study add?

- This large clinical registry analysis provides evidence that when bivalirudin is used, major bleeding outcomes are no different for radial than for femoral access procedures. This study also confirms that the radial procedure is associated with significantly higher radiation exposure than with femoral access procedures.

How might this impact on clinical practice?

- Very low rates of major bleeding can be achieved with the use of bivalirudin. The need to perform radial procedures is less compelling, and there is opportunity for clinical practices to decrease their radiation exposure.

of radial access for some major outcomes. ${ }^{1} 2$ However, RCTs are limited in their ability to generalise findings to clinical practice. The largest RCTs comparing access routes for PCI highlight major biases in patient selection and anticoagulant usage. These study populations tend to have younger patients, fewer females and patients with less anaemia and/ or kidney disease, ${ }^{1-3}$ than populations from clinical experience. ${ }^{4-6}$ Other limitations related to RCTs include less than optimal anticoagulant practices employed during the trial, radial access volume issues and operator skills unrepresentative of clinical practice experiences. $^{2}{ }^{4} 7$ One large RCT (Euromax Trial) suggests that major outcomes do not differ by access site. ${ }^{4}$ Lacking is confirmation of safety outcomes in a large, real-world clinical registry. In the current era of newer 
anticoagulants and adequate numbers of procedures by the transradial approach, a real-world approach reflecting outcomes based on day-to-day clinical experiences is necessary. Using a multisite, contemporary registry of over 58000 PCI procedures in a national healthcare system, the present study compared radial access with femoral access on safety outcomes.

\section{METHODS}

\section{Study design and population}

This is a real-world, large-scale retrospective study using data from a 137-hospital Ascension Health System (AHS) registry. A central repository was initiated with mandatory reporting of 84 well-established data points defined by the ACC/AHA Guidelines on Key Data Elements. ${ }^{8}$ Data were entered prospectively by trained personnel at the time of the heart catheterisation for consecutive patients from all hospitals performing catheterisation in this healthcare system. The database is routinely audited for accuracy and completeness. All patients undergoing a cardiac coronary procedure were included in the database. No patients are excluded. The registry represents procedures and devices as used in routine practice per operator discretion. Sites performing radial procedures were early adoptors with fellowship-trained radialists, training programmes and credentialing. Operators performing radial procedures at these sites are dedicated radialists and experienced in radial access procedures. The most recent 3-year period from 1 June 2009 to 30 June 2012 is included in this study. The study was approved by the institution's review board on 10 October 2012.

\section{Data collection}

Clinical variables collected for the study included demographics, clinical data, devices, intraprocedure and postprocedure events, access site, closure method (all devices, extravascular and intravascular, were grouped together and compression includes manual and mechanical) and discharge status. End points were defined according to the ACC. ${ }^{8}$ The data in this AHS registry are directly reported from the procedure to the registry. This AHS registry reflects current clinical practice at community hospitals in the USA.

\section{Measurements}

The primary end points were major bleeding and radiation exposure. Major bleeding was defined (per ACC criteria) as events of bleeding within 72 hours postprocedure, with at least one of the following: haemoglobin drop $\geq 3 \mathrm{~g} / \mathrm{dL}$, transfusion of whole blood or pack red blood cells and procedural/surgical intervention at the bleed site. Radiation exposure was defined as fluoroscopy time in minutes. All significant complications are captured by the registry.

\section{Statistical analysis}

Outcomes were compared between arterial access sites (radial vs femoral) and anticoagulant therapy groups (heparin vs bivalirudin adjusted for glycoprotein inhibitor (GPI)). Sample size determination for benefit of radial was based on an estimated incidence of the primary end point of $2.5 \%$ in the femoral group with a $40 \%$ decreased rate in the radial group. A sample size of at least 58000 total procedures was needed to account for a radial access group of at least 2800 to achieve $90 \%$ power. This $90 \%$ power was calculated for an $\alpha$ level of 0.05 to show a decrease in the incidence of the primary end point from $2.5 \%$ to $1.5 \%$ as significant. Statistical analysis was performed using the Statistical Package for the Social Sciences, V.18.0 (SPSS, Chicago, Illinois, USA).

Continuous data were expressed as mean $\pm \mathrm{SD}$ and categorical data were expressed as percentage. Differences between groups with continuous data were measured by independent t-test and for categorical data, the differences were measured by $\chi^{2}$ test and OR. Relationships of continuous data to outcome measures were derived by logistic regression modelling adjusted for differences in baseline characteristics observed between groups that potentially influence the outcome of interest. Multivariate logistic regression modelling was used to determine factors independently associated with each outcome. Initial modelling included containing and controlling for potential confounders and interaction terms. The initial model loaded all of the variables into a forward stepwise regression with the variable entry rule set at 0.05 and the removal rule set at 0.10 . Interaction terms for closure method and anticoagulant usage were included. The effect of access site was tested according to group stratification by anticoagulant and antiplatelet usage. Retained within the model were the GPIs. The relative contribution of each measure in the outcome prediction was estimated by the relative increase or decrease in the $\beta$ with the addition of each variable by stepwise fashion. The study was approved and conducted under the regulations of the health system institutional review board. No extramural funding was used to support this work. The authors are solely responsible for the design and conduct of this study, its analysis and the drafting of the paper, as well as its final contents.

\section{RESULTS \\ Overall description}

The registry consists of 93450 cardiac catheter procedures. This analysis was conducted on all 58866 patients undergoing PCI during the registry period. Femoral access $(\mathrm{n}=55729)$ accounted for $94.7 \%$ and radial access $(\mathrm{n}=3137)$ for $5.3 \%$. There were 39379 men $(66.9 \%)$ and 19483 women $(33.1 \%)$. The average age was 64.5 years $( \pm 12.0)$. The majority of patients were Caucasian $(\mathrm{n}=53663,91.2 \%)$. The average BMI was $30.6( \pm 10.8)$ with $80.2 \% \quad(n=47183)$ classified as overweight or obese. 
Diabetes was reported in $22581(38.4 \%)$ patients. ST-elevated myocardial infarction (STEMI) occurred in $7948(13.4 \%)$ patients, and $40.5 \%$ were elective procedures. Unfractionated heparin was used in 39566 $(67.2 \%)$ procedures, bivalirudin in $20808(35.4 \%)$ procedures and GPI in 17486 (29.7\%) procedures. Other anticoagulants included aspirin (89.2\%), clopidogrel $(78.2 \%)$, prasugrel $(13.3 \%)$ and ticlopidine $(0.2 \%)$. Bleeding occurred at an overall rate of $2.1 \% \quad(n=1264)$ and pre-discharge mortality was $1.1 \% \quad(\mathrm{n}=670)$.

\section{Group description}

There were fewer bleeding events in the radial group $(\mathrm{n}=28,0.9 \%)$ than those in the femoral group $(\mathrm{n}=1234$, $2.2 \%)$. Bleeding rates also differed significantly after controlling for GPI usage. Among patients not receiving GPI $(n=41302)$, the femoral bleeding rate was $1.3 \%$ $(\mathrm{n}=515)$ compared with a radial bleeding rate of $0.7 \%$ $(\mathrm{n}=17)$ (relative difference: 46\%, $\mathrm{p}=0.015)$. Among patients receiving GPI $(n=17486)$, the femoral bleeding rate was $4.3 \%(\mathrm{n}=717$ of 16739$)$ compared with the radial bleeding rate of $1.5 \%(\mathrm{n}=11$ of 730$)$ (relative difference: $65 \%, \mathrm{p}<0.001)$. Four other patient characteristics differed by group: race, prior coronary artery bypass graft (CABG), chronic lung disease and STEMI (table 1 ). The radial group had more minority patients, fewer patients with prior CABG or STEMI procedures and slightly more patients with chronic lung disease. Of the other antithrombotic medications (aspirin,

Table 1 Characteristics of the two access site groups

\begin{tabular}{|c|c|c|c|}
\hline Total $58825^{\star}$ & $\begin{array}{l}\text { Femoral } \\
\text { n (\%) } \\
55781(94.8)\end{array}$ & $\begin{array}{l}\text { Radial } \\
\text { n (\%) } \\
3044(5.2)\end{array}$ & p Value \\
\hline Male & $37282(66.8)$ & 2068 (67.9) & 0.21 \\
\hline Caucasiant & 50897 (91.2) & 2731 (89.7) & 0.01 \\
\hline Age (mean, SD) & 64.5 (12.0) & 64.2 (11.9) & 0.30 \\
\hline Current smoker & $16500(29.6)$ & $921(30.3)$ & 0.46 \\
\hline Hypertension & 47291 (84.9) & 2607 (85.6) & 0.26 \\
\hline Dyslipidaemia & 47708 (85.5) & 2622 (86.1) & 0.39 \\
\hline Prior MI & 19795 (35.5) & 1077 (35.4) & 0.90 \\
\hline Prior HF & 7750 (13.9) & 424 (13.9) & 0.97 \\
\hline Prior PCI & 25552 (45.8) & 1339 (44.0) & 0.06 \\
\hline Prior CABG† & 12076 (21.6) & 402 (13.2) & 0.000 \\
\hline Prior PAD† & 7774 (14.0) & $528(6.4)$ & 0.000 \\
\hline Kidney disease & $1019(1.8)$ & $48(1.6)$ & 0.36 \\
\hline $\begin{array}{l}\text { Chronic lung } \\
\text { disease }\end{array}$ & $10438(18.7)$ & $673(22.1)$ & 0.000 \\
\hline Diabetes & 21376 (38.3) & 1188 (39.0) & 0.44 \\
\hline STEMI† & 7696 (13.8) & 250 (8.2) & 0.000 \\
\hline Complex lesion† & $25220(45.4)$ & 1294 (42.7) & 0.005 \\
\hline Bivalirudin† & 19590 (35.1) & 1209 (39.7) & 0.000 \\
\hline GPI† & $16743(30.0)$ & 730 (24.0) & 0.000 \\
\hline Prasugrel† & 7189 (12.9) & 635 (20.9) & 0.000 \\
\hline 72-hour bleed & $1234(2.2)$ & $28(0.9)$ & 0.000 \\
\hline
\end{tabular}

clopidogrel, prasugrel and ticlopidine), only prasugrel differed by access site group. The following analyses were adjusted for these characteristics.

\section{Comparative analysis}

Univariate analysis demonstrated a significantly lower bleeding rate in the radial group versus the femoral group $(0.9 \%$ vs $2.2 \%$; OR $=0.4$, CI 0.3 to 0.6$) \quad\left(\chi^{2}=22.9\right.$, $\mathrm{p}<0.01)$. After controlling for GPI use, the bleeding rate differential diverged significantly $(\mathrm{OR}=0.45, \mathrm{p}<0.001)$. For patients not receiving GPI, bleeding rate for radial access was $0.7 \%$ and for femoral access the rate was $1.3 \%$ or a difference of $0.6 \%(\mathrm{OR}=0.56$, CI 0.34 to 0.91 , $\mathrm{p}=0.02$ ). For patients receiving GPI, bleeding rate for radial access was $1.5 \%$ and for femoral access the rate was $4.3 \%$ or a difference of $2.8 \% \quad(\mathrm{OR}=0.34$, CI 0.18 to $0.62, \mathrm{p}<0.001$ ) (figure 1).

A multilogistic regression analysis was conducted to adjust for variables that differed significantly by access site group (from table 2). Radial access continued to be an independent predictor of lower bleeding rates after adjustment for patient characteristics $(\beta=-0.81$, Wald $=17.5, \mathrm{OR}=0.45$, CI 0.31 to $0.66, \mathrm{p}<0.001$ ) and for GPI use $(\beta=-0.77$, Wald $=16.0, \mathrm{OR}=0.46$, CI 0.32 to 0.87 , $\mathrm{p}<0.001)$. However, when the analysis controlled for anticoagulant usage, bleeding rates by access site became equivocal among patients receiving bivalirudin, while heparin patients continued to see a bleeding benefit with radial access. For patients receiving bivalirudin, bleeding occurred in 337 patients $(1.6 \%)$ and there was no difference in rates between radial access $(n=13,1.1 \%)$ and femoral access $(\mathrm{n}=327,1.7 \%) \quad(\beta=-0.4$, Wald $=1.9$, $\mathrm{OR}=0.65$, CI 0.40 to $1.22, \mathrm{p}=0.19$ ). For patients receiving heparin, bleeding occurred in 920 patients $(2.4 \%)$ and there was a significant advantage to radial access $(n=15$, $0.8 \%)$ compared with femoral access $(\mathrm{n}=905,2.5 \%)$ in terms of bleeding rates $(\beta=-0.9$, Wald $=11.7, \mathrm{OR}=0.39$, CI 0.23 to $0.67, \mathrm{p}=0.001$ ) (figure 2 ).

\section{Safety}

Radiation exposure was examined. For all patients, the average fluoroscopy time was $14.5 \mathrm{~min}( \pm 11.0$, range:

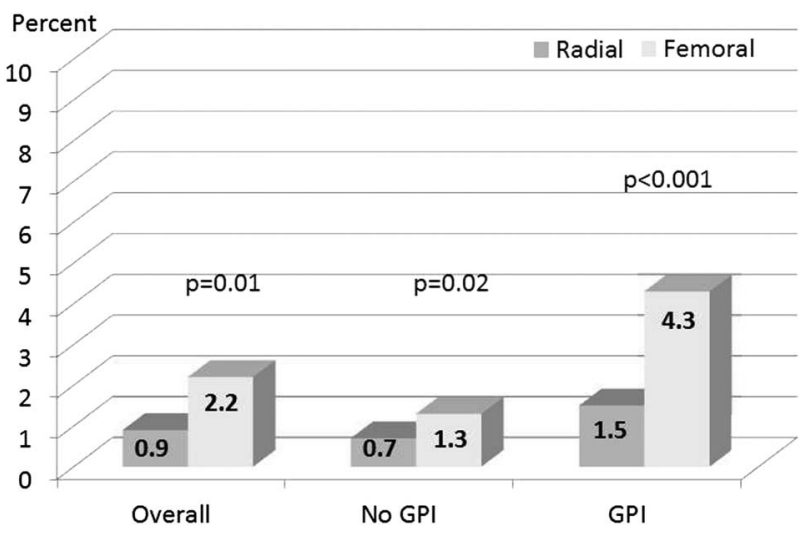

Figure 1 Bleeding rates by access site and glycoprotein inhibitor usage. 
Table 2 Multiple regression model of bleeding outcome for each anticoagulant

\begin{tabular}{lrrlll}
\hline & $\boldsymbol{\beta}$ & Wald & $\mathbf{p}$ Value & OR & Cl \\
\hline Heparin & & & & & \\
Race & -0.16 & 1.9 & 0.16 & 0.8 & 0.67 to 1.07 \\
CLD & 0.80 & 101.3 & 0.000 & 2.2 & 1.9 to 2.6 \\
TEMI & -1.0 & 171.4 & 0.000 & 0.4 & 0.31 to 0.42 \\
GPI & 1.0 & 145.8 & 0.000 & 2.7 & 2.3 to 3.2 \\
Prasugrel & -0.63 & 22.1 & 0.000 & 0.5 & 0.41 to 0.69 \\
Access site & -0.93 & 11.8 & 0.001 & 0.4 & 0.23 to 0.67 \\
Bivalirudin & & & & & \\
Race & -0.15 & 0.8 & 0.39 & 0.8 & 0.61 to 1.2 \\
CLD & 0.14 & 1.1 & 0.30 & 1.2 & 0.89 to 1.51 \\
STEMI & -0.97 & 38.3 & 0.000 & 0.4 & 0.28 to 0.52 \\
GPI & 0.99 & 45.7 & 0.000 & 2.7 & 2.0 to 3.6 \\
Prasugrel & -0.42 & 6.6 & 0.01 & 0.6 & 0.47 to 0.90 \\
Access site & -0.42 & 1.9 & 0.16 & 0.7 & 0.36 to 1.2 \\
\hline${ }^{*}$ Wald=test statistic. & & & & &
\end{tabular}

$0-300)$. This differential remained consistent regardless of prior CABG surgery. The average fluoroscopy time among patients with no history of prior CABG was 13.7 min ( \pm 10.5 , range: $0-300)$. The average fluoroscopy time among patients with a history of CABG was 17.6 $( \pm 12.2$, range: $0-180)$. Radiation exposure for all patients was similar, although statistically differed, by PCI indication. STEMI procedures resulted in an average fluoroscopy time of $13.7 \mathrm{~min}( \pm 10.5)$, while non-STEMI (NSTEMI) procedures had an average time of $14.6 \mathrm{~min}$ $( \pm 11.1)$.

However, previous history of CABG and STEMI procedures showed a difference in exposure time benefitting the femoral access site (table 3). Femoral access resulted in significantly less exposure than radial access regardless of CABG history or of PCI indication $(p<0.001)$. The radial technique resulted in higher radiation exposure in each case, particularly for procedures involving prior CABG history and NSTEMI patients (table 4 and figure 3). Fluoroscopy time was examined for higher risk patients; those with previous CABG, previous PAD, STEMI or having complex lesions. The mean

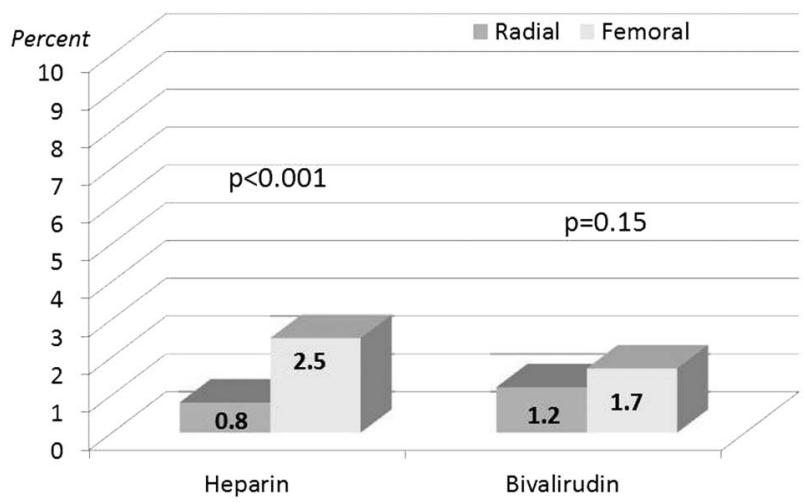

Figure 2 Adjusted bleeding rates by access site and anticoagulant usage. fluoroscopy time among femoral access procedures was $15.68 \mathrm{~min}( \pm 11.7)$ versus $19.86 \mathrm{~min}( \pm 13.8)$ for radial access procedures $(p<0.0001)$. For lower risk patients, those without previous CABG, previous PAD, with NSTEMI and having non-complex lesions, the mean time among femoral access procedures was $14.19 \mathrm{~min}$ $( \pm 10.7)$ versus $18.01( \pm 12.3)$ for radial access procedures. In both cases, higher risk and lower risk patients, radiation exposure was significantly higher among radial procedures compared with femoral procedures.

\section{DISCUSSION}

RCTs have suggested radial access superiority in terms of major bleeding and/or major adverse outcomes. ${ }^{9}{ }^{10}$ These findings are somewhat limited in terms of protocols and selected patients who do not represent routine clinical practice. Other RCTs demonstrate no difference in major bleeding outcomes, ${ }^{2}{ }^{3}$ no difference in major adverse outcomes ${ }^{1}$ and one trial showed a difference for STEMI but not for NSTEMI patients. ${ }^{2}$ The equivocal

Table 3 Radiation exposure (fluoroscopy time in minutes)

\begin{tabular}{|c|c|c|c|c|}
\hline & $\begin{array}{l}\text { Femoral } \\
\mathrm{n}=55459 \\
\text { mean } \\
(\mathrm{SD})\end{array}$ & $\begin{array}{l}\text { Radial } \\
\mathrm{n}=3033 \\
\text { mean } \\
(\mathrm{SD})\end{array}$ & p Value & $\begin{array}{l}\text { RD } \\
(\%)\end{array}$ \\
\hline $\begin{array}{l}\text { Overall } \\
n=58492\end{array}$ & $14.3(10.9)$ & $18.2(12.3)$ & $<0.0001$ & 21.4 \\
\hline $\begin{array}{l}\text { CABG history } \\
n=12398\end{array}$ & $\begin{array}{l}17.4(12.0) \\
\mathrm{n}=11999\end{array}$ & $\begin{array}{l}23.3(15.2) \\
n=399\end{array}$ & $<0.0001$ & 25.3 \\
\hline $\begin{array}{l}\text { NSTEMI } \\
n=50589\end{array}$ & $\begin{array}{l}14.4(10.9) \\
n=47805\end{array}$ & $\begin{array}{l}18.3(12.5) \\
n=2784\end{array}$ & $<0.0001$ & 21.3 \\
\hline $\begin{array}{l}\text { CABG and } \\
\text { NSTEMI } \\
n=11803\end{array}$ & $\begin{array}{l}17.4(12.1) \\
\mathrm{n}=11410\end{array}$ & $\begin{array}{l}23.4(15.3) \\
n=393\end{array}$ & $<0.0001$ & 25.6 \\
\hline
\end{tabular}


Table 4 Radiation exposure (fluoroscopy time in minutes) by anticoagulant

\begin{tabular}{llll}
\hline & $\begin{array}{l}\text { Heparin } \\
\text { mean (SD) }\end{array}$ & $\begin{array}{l}\text { Bivalirudin } \\
\text { mean (SD) }\end{array}$ & p Value \\
\hline Prior CABG: no & & \\
$\quad$ Radial & $16.7(10.9)$ & $18.4(12.7)$ & $<0.001$ \\
Femoral & $13.3(10.5)$ & $13.8(10.3)$ & $<0.001$ \\
RD (\%) & $20.3(p<0.0001)$ & $25.0(p<0.0001)$ & \\
Prior CABG: yes & & \\
Radial & $21.4(16.8)$ & $25.4(12.7)$ & $<0.001$ \\
Femoral & $16.9(12.2)$ & $18.2(11.6)$ & $<0.001$ \\
RD (\%) & $21.0(p<0.0001)$ & $28.4(p<0.0001)$ & \\
\hline CABG, coronary artery bypass graft; RD, relative difference.
\end{tabular}

findings of RCTs regarding efficacy for radial access may be a reflection of its biggest limitation-variability in protocol and patient selection. Regardless of conflicting findings, this variability limits the generalisability of the results. Wide variances in the use of GPIs, over 30\% in one study, confound the study applicability to clinical practice. ${ }^{7}$ In practice, anticoagulant practices vary widely, sicker patients are more likely to be directed to femoral access and many are not high-volume radial centres. Complications may therefore differ greatly between clinical trials and clinical practice.

Clinical registry studies provide for improved generalisability where they are multicentre, enrolment is all comers and include large numbers. Two of the larger registry studies demonstrated significantly lower bleeding and mortality rates among radial access procedures. ${ }^{4}{ }^{11}$ However, their findings may be limited due to data that were captured from billing codes which may not be timely or reflective of actual clinic practice. Registries that are based on clinical procedure data have greater generalisability in terms of accurate, timely depiction of clinical practice. The largest registry comparison of arterial access to date is an analysis from the National Cardiovascular Data Registry (2007-2011) in which 294769 patients was enrolled. ${ }^{5}$ This registry concentrated on STEMI patients only and reflects older clinical

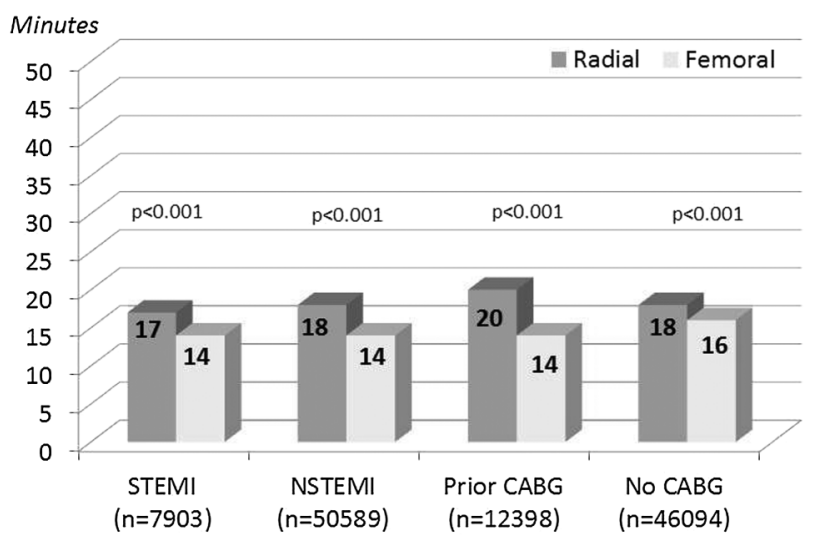

Figure 3 Fluoroscopy time by arterial access per risk. practice patterns. Patients in this registry were enrolled between 2007 and 2011 and included a bivalirudin usage rate of $<0.5 \%$. Our registry reflects current clinical practices from 2012 and includes bivalirudin use rates of $35 \%$ or more. It is the largest registry of all admissions to the catheter laboratory and is the most representative of non-selective clinical practice currently. To date, the only other clinical-based registries of all comers comparing radial with femoral access for PCI involve small numbers not representative of a broad range of procedures. $^{12-16}$

Major bleeding patterns have significantly changed since 2007. Current rates of major bleeding are below $2 \%$ on average and other studies have suggested equivalent bleeding rates between access site when bivalirudin is used. $^{2} 1718$ This finding is confirmed in this large multisite clinical registry. Among 58862 PCI procedures of all comers across 137 hospitals, our analysis demonstrated no difference in major bleeding rates for patients receiving bivalirudin (figure 2). This is despite the radial group having a relative $40 \%$ lower STEMI rate and lower prior CABG rate (table 1) and the femoral group having a $38 \%$ higher rate of emergency procedures $(14.5 \%$ vs $9.0 \%$, $\mathrm{p}<0.0001)$, suggesting that femoral access is a default strategy for the sicker patients in clinical practice.

An updated examination of radial access adoption by Feldman $e t a l^{19}$ confirms in their descriptive results our findings that femoral access is significantly more likely to have sicker patients (previous CABG $19.3 \%$ vs $8.9 \%$ radial, $\mathrm{p}<0.01$ ) (emergent cases $20.6 \%$ vs $10.6 \%$ radial, $\mathrm{p}<0.01$ ) (STEMI patients $18.9 \%$ vs $10.6 \%$ radial, $\mathrm{p}<0.01$ ). However, they report significantly lower bleeding rates among radial than among femoral procedures. Although they employed a similar model to ours for controlling factors that differ between the groups, they pulled a significant number of procedures from the final analysis-all sites that do only femoral were eliminated. This final analysis is a constructed comparison rather than a reflection of real-world all comers' results. The procedures pulled from the analysis were only femoral access procedures, which may have biased the bleeding rates comparison with bivalirudin. In addition, the authors used their bleeding risk score in the adjusted model which may over control for patient differences. It would be difficult to reproduce these results from analyses with such varied model adjustments and thus makes it difficult to apply their findings to clinical practice. Our findings are in stark contrast to other findings on bleeding in part may be due to this study not removing femoral or radial procedures for the analysis, not making multiple adjustments and not being supported by outside funding.

The safety of the patient and the operator in terms of radiation exposure also need to be addressed in the light of current studies failing to definitively demonstrate radial superiority in terms of major patient outcomes. Among patients in the current registry, radiation exposure was significantly higher among radial procedures 
compared with femoral procedures (table 3). These findings confirm what others have reported regardless of whether exposure was measured by radiation dose or fluoroscopy time or whether experienced operators were used. ${ }^{20-22}$ Although procedural, and hence fluoroscopy, times vary across sites, our finding of a $20 \%$ effect differential is consistent with other published findings of effect sizes in favour of femoral access ranging from $15 \%$ to $38 \%$.

This analysis is the largest clinical registry of contemporary treatment practices comparing radial and femoral access outcomes among all comers. The data are based on clinically reported procedure data among over 58000 all-comers to a multisite registry that includes high and lower volume centres. The database represents a broad range of procedures, STEMI and NSTEMI, as well as a broad range of patient risks and operator experiences. Findings on safety outcomes have high generalisability for patients and providers to routine practices here in the USA. A limitation of any registry analysis is the differences in patient characteristics between the two groups. However, we controlled for differences in baseline and procedural characteristics with a stepwise, multivariate regression analysis. Radial procedures are more likely to be performed in less complicated, less sick patients. For example, patients with prior bypass surgery were significantly more likely to receive femoral access (table 1). The registry also did not include how many failed radial routes were converted to femoral procedures after initiation. In so much as the regression analysis undercontrolled for a differential factor, the results may be underestimated or overestimated. Another limitation is the age of the data set. The most recent 3-year period used was up to 2012 and may not reflect 2015 practices. Even so, this registry reveals the clinical reality that sicker patients more often get femoral access and have more complex procedures that require longer times. Despite this, we observed femoral access to result in significantly lower radiation exposure than radial access procedures while maintaining similar bleeding rates with bivalirudin usage. A registry also does not account for bias related to operator experience and learning curves. However, most of the learning curve is in gaining access when fluoroscopy has not been initiated. The radiation exposure occurs during the route to the ascending aorta from the radial access that is not an issue for femoral procedures. These differences highlight the safety issues that this registry of routine clinical practice attempts to address. Despite controlling for patient and procedure differences, we observed a higher rate of radiation exposure among the radial group.

\section{Conclusion}

Radial access procedures for PCI are associated with greater radiation exposure but not with less major bleeding than femoral access procedures when bivalirudin is used.
Competing interests None declared.

Ethics approval Genesys Health System review board.

Provenance and peer review Not commissioned; externally peer reviewed.

Open Access This is an Open Access article distributed in accordance with the Creative Commons Attribution Non Commercial (CC BY-NC 4.0) license, which permits others to distribute, remix, adapt, build upon this work noncommercially, and license their derivative works on different terms, provided the original work is properly cited and the use is non-commercial. See: http:// creativecommons.org/licenses/by-nc/4.0/

\section{REFERENCES}

1. Valgimigli $M$, Calabro $P$, Frigoli $E$, et al., MATRIX Investigators. Radial versus femoral access in patients with acute coronary syndromes undergoing invasive management: a randomized multicenter trial. Lancet 2015;385:2465-76.

2. Jolly S, Usuf $\mathrm{S}$, Cairns J, et al., RIVAL trial group. Radial versus femoral access for coronary angiography and intervention in patients with acute coronary syndromes (RIVAL): a randomized, parallel group, multicenter trial. Lancet 2011;377:1409-20.

3. Chase AJ, Fretz EB, Warburton WP, et al. Association of the arterial access site at angioplasty with transfusion and mortality: the M.O.R. T.A.L study (mortality benefit of reduced transfusion after percutaneous coronary intervention via the arm or leg). Heart 2008;94:1019-25.

4. Hamon M, Coste P, Van't Hof A, et al. Impact of arterial access site on outcomes after primary percutaneous coronary intervention: prespecified subgroup analysis from the EUROMAX trial. Circ Interv 2015;8:e002049.

5. Baklanov DV, Kaltenbach LA, Marso SP, et al. The prevalence and outcomes of transradial percutaneous coronary intervention for ST-segment elevation myocardial infarction: analysis from the National Cardiovascular Data Registry (2007 to 2011). J Am Coll Cardiol 2013;61:420-6.

6. Dobies DR, Barber KR, Cohoon AL. Gender Differences in percutaneous coronary intervention: outcomes from a clinical registry of 59,000 PCl's. New insights into management and mechanisms of heart disease. In: Proceedings of the International Academy of Cardiology 18th World Congress on Heart Disease. 26-29 July. Vancouver, BC: Canada. Annual Scientific Sessions, 2013.

7. Shahzad A, Kemp I, Mars C, et al., HEAT-PPCl trial investigators. Unfractionated heparin versus bivalirudin in primary percutaneous coronary intervention (HEAT-PPCI): an open-label, single center, randomized controlled trial. Lancet 2014;384:1849-58.

8. Cannon CP, Brindis RG, Chaitman BR, et al. 2013 ACCF/AHA key data elements and definitions for measuring the clinical management and outcomes of patients with acute coronary syndromes and coronary artery disease: a report of the American College of Cardiology Foundation/American Heart Association Task Force on clinical data standards (writing committee to develop acute coronary syndromes and coronary artery disease clinical data standards). Circulation 2013;127:1052-89.

9. Romagnoli E, Biondi-Zoccai G, Sciahbasi A, et al. Radial versus femoral randomized investigation in ST-segment elevation acute coronary syndrome: the RIFLE-STEACS (Radial versus Femoral Randomized Investigation in ST-Elevation Acute Coronary Syndrome) study. J Am Coll Cardiol 2012;60:2481-9.

10. Bernat I, Horak D, Stasek J, et al. ST-segment elevation myocardial infarction treated by radial or femoral approach in a multicenter randomized clinical trial: the STEMI-RADIAL Trial. J Am Coll Cardiol 2014;63:964-72.

11. Mamas M, Ratib K, Routledge $\mathrm{H}$, et al., British Cardiovascular Intervention Society and the National Institute for Cardiovascular Outcomes Research. Influence of arterial access site selection on outcomes in primary percutaneous coronary intervention: are the results of randomized trials achievable in clinical practice? JACC Cardiovasc Interv 2013;6:698-706.

12. Bauer T, Hochadel M, Brachmann J, et al. Use and outcome of radial versus femoral approach for primary $\mathrm{PCl}$ in patients with acute ST elevation myocardial infarction without cardiogenic shock: results from the ALKK PCI Registry. Catheter Cardiovasc Interv 2015;86 (Suppl 1):S8-14.

13. Cantor W, Ko D, Natarajan M, et al. Reperfusion times for radial versus femoral access in patients with ST-elevation myocardial infarction undergoing primary percutaneous coronary intervention: observations from the cardiac care network provincial primary $\mathrm{PCl}$ registry. Circ Cardiovasc Interv 2015;8:1-7. 
14. Kedev S, Kalpak O, Dharma S, et al. Complete transitioning to the radial approach for primary percutaneous coronary intervention: a real-world single-center registry of 1808 consecutive patients with acute ST-elevation myocardial infarction. J Invasive Cardiol 2014;26:475-82.

15. Andrade PB, Andrade MV, Barbosa RA, et al. Femoral versus radial access in primary angioplasty. Analysis of the ACCEPT Registry. Arq Bras Cardiol 2014;102:566-70.

16. Decarlo M, Borelli G, Gistri R, et al. Effectiveness of the transradial approach to reduce bleedings in patients undergoing urgent coronary angioplasty with GPIIb/IIla inhibitors for acute coronary syndromes. Catheter Cardiovasc Interv 2009;74:408-15.

17. Pinto $D$, Kohli $P$, Fan $W$, et al. Bivalirudin is associated with improved clinical and economic outcomes in heart failure patients undergoing percutaneous coronary intervention: results from an observational database. Catheter Cardiovasc Interv 2016;87:363-73.

18. Dobies DR, Barber KR, Cohoon AL. Clinical utility of a bleeding risk score tool for patients undergoing percutaneous coronary intervention based on body mass index. Open Heart 2015;2:e000088.
19. Feldman DN, Swaminathan RV, Kaltenbach LA, et al. Adoption of radial access and comparison of outcomes to femoral access in percutaneous coronary intervention: an updated report from the National cardiovascular Data Registry (2007-2012). Circulation 2013;127:2295-306.

20. Shah B, Bangalore S, Feit F, et al. Radiation exposure during coronary angiography via transradial or transfemoral approaches when performed by experienced operators. Am Heart $J$ 2013;165:286-92

21. Jolly S, Cairns J, Niemela K, et al., RIVAL Investigators. Effect of radial versus femoral access on radiation dose and the importance of procedural volume: a substudy of the multicenter randomized RIVAL Trial. JACC Cardiovasc Interv 2013;6:258-66.

22. Plourde G, Pancholy S, Nolan J, et al. Radiation exposure in relation to the arterial access site used for diagnostic coronary angiography and percutaneous coronary intervention: a systematic review and meta-analysis. Lancet 2015;386:2192-203. 